\title{
Design and Verification of Selected Technological Procedures for the Repairs of Land Vehicles Combat Damage
}

\author{
Jan Furch, Josef Glos, Adam Švásta \\ College of Department Combat and Special Vehicles, University of Defence, Brno, Czech Republic \\ Email: jan.furch@unob.cz
}

Received 2 August 2014; revised 17 September 2014; accepted 2 October 2014

Academic Editor: Gustav Šafr, Emeritus of the University of Defence, Czech Republic

Copyright (C) 2014 by authors and Scientific Research Publishing Inc.

This work is licensed under the Creative Commons Attribution International License (CC BY). http://creativecommons.org/licenses/by/4.0/

\section{(c) (i) Open Access}

\begin{abstract}
The paper deals with temporary repairs. Applying a different technology, using a reproduction part, or performing a repair by a serviceman without the competence is typical features of temporary repairs. Temporary repair makes possible for an object to fulfil its function for a limited time, until regular repairs can be made. The complexity perplex modern vehicles their reparability. It is necessary to look for the new procedures of the implementation so-called temporary repairs. The authors suggested procedure battle damage assessment and repair, which they expressed in the form of diagrams. There is also description of new technological procedures, which could be possibly applied in field of temporary repairs. These new procedures are applied on land (wheeled and tracked) vehicles parts and their sufficiency for Czech Army conditions is tested. The main purpose of the thesis is defining operating procedures of the most useful methods, including their verifications and proposal of tools needed for repairs. These tools should be included in equipment of vehicles operated in Czech Army. The thesis is primarily focused on repairs of mechanical parts and units and also of reparation of fuel, hydraulic and high pressure systems.
\end{abstract}

\section{Keywords}

Battle Damage Assessment and Repair (BDAR), Temporary Repair (TR), Field Conditions, Adhesive Composites

\section{Introduction}

Battle damage repair (BDR) can play a key role in the outcome of a war but also in the peace. Promptness, re-

How to cite this paper: Furch, J., Glos, J. and Švásta, A. (2014) Design and Verification of Selected Technological Procedures for the Repairs of Land Vehicles Combat Damage. World Journal of Engineering and Technology, 2, 269-280. 
liability, and effectiveness of repairs affect the availability of land vehicles for use in emergency situations.

In present Czech Army units carry out duties, which are connected with those carried out by NATO alliance. These missions are on first place connected with deployment in peacekeeping operations in abroad. The main objective which is required is that units composed of few vehicles have to departure for long distances from bases; it can be tens of kilometers. This fact lays stress on crew self-sufficiency for example in situations of selfrecovery, but also in cases of technical faults and lighter failures solution. Those failures can cause vehicle immobility.

Another motivation to permanent introduction and improvement of means used for temporary repairs is the fact, that activity of enemy causes just about 40 percent damages of vehicles. To this number can be counted damages caused by IED explosion or hit by anti-armour weapons. The majority of cases it is a direct result of improper use of technology (i.e. raid on uneven terrain or obstacle at high speed, or due to accident) or random failure of components. Big part of those failures could be easily restored without necessity of excessive efforts and without usage of special NATO Stock Number (NSN) or represented spare parts [1].

High-risk battle damage repairs (involving possible danger to personnel or further damage to equipment) are only permitted in emergencies, normally in a battlefield environment, and only when authorized by the unit commander or his designated representative. The goal is to return a combat system to the battlefield in the least amount of time, while minimizing danger to personnel and equipment.

Battle Damage Assessment and Repair (BDAR) techniques are not limited to simply restoring minimal functional combat capability. If full mission capability can be restored expediently with a limited expenditure of time and assets, it should be restored.

Some BDAR techniques, if applied, may result in shortened lifespan or further damage to components. The commander must decide whether the risk of having one less piece of equipment outweighs the risk of applying a potentially destructive field-expedient repair. Each technique provides appropriate warnings and cautions, which list the system's limitations caused by the action. Personnel must use ground guides and extreme caution when operating recovery assets.

\section{The Significance of Temporary Repairs}

The standard ISO EN 13306 defines temporary repairs of vehicles such as: "Physical interventions which enable to perform function for limited period to object which was in failure state, until moment of regular reparation execution” [2]. In past, temporary repair evolution was carried out spontaneously, according circumstances which were needed to deal with. Temporary repair depended on crew experience, on the level of vehicle complexity, on technical contingency and also on skill of individuals. Typical attribute of temporary repairs is another technology, not original part application or repair executing out of repairer competence.

Battle Damage Assessment (BDA) is the process used to quickly identify primary and secondary damage. Battle damage repair is accomplished by bypassing components or safety devices, cannibalizing or controlled Exchange of parts from like or lower priority equipment, fabricating repair parts, jury-rigging, taking shortcuts to standard maintenance, and using substitute fluids, materials or components.

During the BDA process, it is important to perform an "equipment triage". Triage is a process used to determine which systems are mission critical and the priority of repairs to restore function and return to service.

The battlefield is a chaotic environment with many unexpected circumstances. After performing triage, repair only what is needed, spending time on non-essential repairs is a waste of resources. Specific repair procedures may not be listed in technical or field manuals, and repair parts, tools, and skilled personnel may not be available. Flexibility and ingenuity are crucial to successful performance of BDAR.

The main principles of temporary repair are [3]:

- visually inspect interior and exterior for damaged parts and systems;

- visually determine if vehicle main systems appear to be operable;

- perform equipment self-test function-using a built-in test, built-in test equipment, and a function test;

- find out if the repair need to be executed immediately or can be postponed to arrival to unit post;

- determine technical state of vehicles parts, which have to be repaired;

- decide about the availability of means needed for repair execution;

- consideration of the economic performance of the repair (temporary and regular);

- consideration of the risk of the situation towards saving lives and vehicles;

- estimate required experience and skill of vehicle crew to execute repair; 
- estimate time needed to carry out the repair;

- determine what materials are required;

- repair only what is necessary to regain combat capability;

- analyses the real state and decide about calling in supporting forces including specialists;

- determine what the vehicle limitations will be after repairing using BDAR or standard repair.

From mentioned facts arise that temporary repair system should be projected for each type of land vehicle (wheeled and tracked vehicles) separately. Executions of temporary repair suppose also carrying out repairs training in battlefield conditions.

The following safety checks are performed to identify any obvious hazard as:

- Is there a round of ammunition in the gun tube?

- Is any ammunition in a critical state due to shock, fire, or physical damage?

- Have any combustibles such as fuel, hydraulic fluid, or oil accumulated?

- Does wiring appear to be safe? Could an arc occur to stored ammunition or leaking combustibles?

- Is the fire-extinguishing system operational? If not, station a crewmember in the vehicle prepared either to use a handheld fire extinguisher or to operate the on board fire extinguishing system manually. Station a second crewmember outside the vehicle with an additional fire extinguisher.

- For systems with built-in self-test procedures, has a functional/operator test been performed on those systems that appear undamaged?

\section{Principles of Expedient (Temporary) Repairs}

In the past the temporary repairs of military combat vehicles proceeded spontaneously and depended on the circumstances to be dealt with. The repair progress was influenced by experiences, the level of combat vehicle complexity, technical facilities and individual skills. Applying a different technology, using a reproduction part, or performing a repair by a serviceman without the competence is typical features of temporary repairs.

It is good to realize that the temporary repair of combat vehicles cannot adequately substitute the repair performed in compliance with technical conditions and that is the reason why the next repair should be carried out in the shortest term. The reason for performing a regular repair is that a nonstandard procedure does not provide for dependability. In spite of all drawbacks, the temporary repairs can play an important part in a combat operation.

\subsection{Theoretical Principles of Temporary Repairs in Peace}

The aim of a temporary repair in peace time is to renew or partly renew mobility and to prevent from more extensive damage, as for example environmental pollution caused by the leak of hazardous substances, safety threat by making a trouble in operation, or the devaluation of a transported material.

Operating costs are not expected to be increased due to the temporary repair, therefore, when deciding whether to perform it, economical factor will be the main criterion. The economical factor can be expressed by the following formula [3]

$$
N_{O}+N_{D O}+N_{Z t D O} \leq N_{O}+N_{Z t O},
$$

where $N_{O}$ - the costs of performing the repair, $N_{D O}$-the temporary repair costs, $N_{Z t D O}$-the loss incurred by the time the temporary repair is performed, and $N_{Z t o}$-the loss incurred by the time the repair is performed.

The loss can include the costs of the settlement of a possible breakdown, the devaluation of a transported material, penalty payments, repair assistance, the costs of reloading material, the recovery and evacuation of a vehicle, or the increased costs of the repair due to the wear-out caused by performing the temporary repair. After modifying the Equation (1), we get [3]

$$
N_{D O} \leq N_{Z t O}-N_{Z t D O}
$$

which is an economical requirement for performing the temporary repair. However, even much higher costs of performing the temporary repair as compared with the repair costs might be justified in this way, therefore the following formula must apply simultaneously

$$
N_{D O} \leq N_{O}
$$

and then it holds 


$$
\left(N_{D O} \leq N_{Z t O}-N_{Z t D O}\right) \cap\left(N_{D O} \leq N_{O}\right) .
$$

When deciding whether to perform the temporary repair, we should take into account not only the costs, but also the fact to what extent a vehicle or a workshop vehicle is equipped with tools and material, to what degree a vehicle can be adapted to temporary repair performance, and the level of operating personnel skills.

Another important factor used when we are to agree on performing the temporary repair is time $t_{\min }$, during which it is necessary to assure the main function of a temporarily repaired part until a regular repair is performed. The information stated above is followed by a requirement limiting the costs of temporary repair performance

$$
N_{D O} \leq t_{\min } \frac{N_{Z t O}-N_{Z t D O}}{\mathrm{~d} t} .
$$

Therefore, when deciding whether to perform the temporary repair in peace time, it holds [1]

$$
\left(N_{D O} \leq N_{O}\right) \cap\left(N_{D O} \leq t_{\min } \frac{N_{Z t O}-N_{Z t D O}}{\mathrm{~d} t}\right) .
$$

\subsection{Theoretical Principles of Temporary Repairs in Field Conditions}

The difference between the temporary repairs of combat vehicles performed in peace time and in field conditions is that we follow not only economical factors which are the most important in peace time, but also the provision of combat vehicle main functions, e.g. a weapon system, vehicle mobility and communication. The survival time of a vehicle (a crew) in a battlefield is crucial for deciding whether to perform the temporary repair. To put it simply, the recovery process of combat vehicle fighting power might be viewed as a geometric sequence [3]:

$$
n_{t}=n_{0} q^{t-1},
$$

where $n_{0}$ is the number of combat vehicles before the operation began, $n_{t}$ is the number of combat vehicles at the beginning of the day $t, q$ is a sequence quotient, $t$ - the number of days.

The magnitude of the sequence quotient $q$ can be described as the ability to repair damaged combat vehicles with the extension of loss $z$, combat vehicle repairability $\psi$, and when considering the capacity and technical possibility of performing the repair with repair units $\varepsilon$.

Therefore

$$
q=1-z+\psi \varepsilon z
$$

Then, sustainability time is given by a decrease in the number of combat vehicles at an acceptable level $n_{x}$

$$
n_{x}=n_{0} \cdot q^{t_{x}-1}
$$

and therefore

$$
t_{x}=\frac{\log n_{x}-\log n_{0}}{\log q}+1
$$

when reaching the time $t_{x}$ a unit must be replaced or supplied by another combat vehicle [1].

Performing temporary repairs helps to increase the capacity of repair units by labour saving, overcoming downtime due to the lack of spare parts, or involving crews in the repair process. This will be manifested in the rise in coefficient value $\varepsilon$.

Graph 1 shows the courses of the decrease in fighting power with average 15\% daily losses $z$, the limit of $60 \%$ fighting power and different magnitudes $\psi$ and $\varepsilon$.

The courses of single curves show that extending the capacity of repair units has a positive impact on the fighting power time of supplied units, e.g. when performing temporary repairs.

\section{Procedure Battle Damage Assessment and Repair}

This chapter introduces procedures for dealing with battle damage assessment and repair (BDAR). Using these guidelines helps in a short time assess battle-damaged equipment and systematically determines which subsystems are affected including time, personnel, and materials required for repair.

These guidelines will also assist in performing an "equipment triage". The equipment triage is the process 


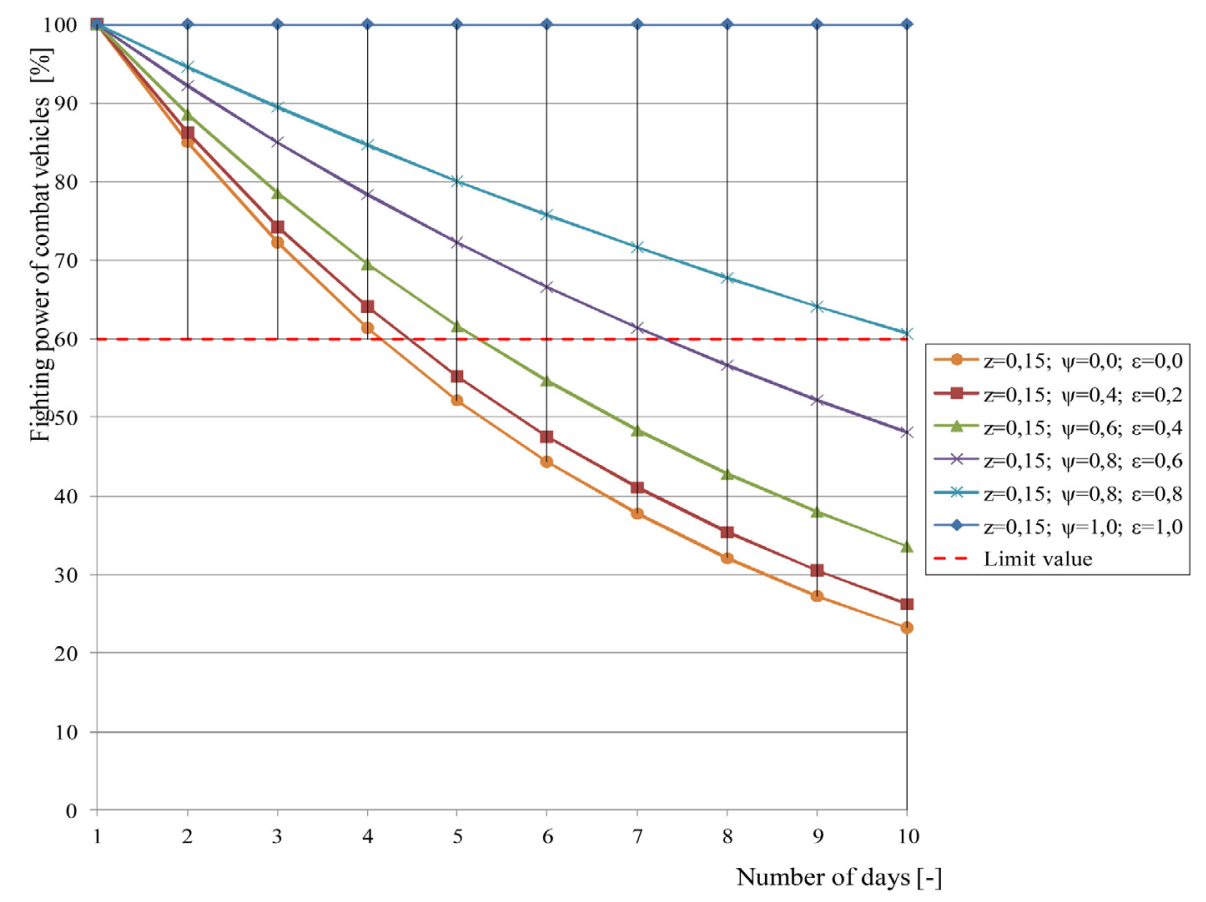

Graph 1. Fighting power of combat vehicles with 15\% daily losses. (Own Source)

used to decide in which order the battle damaged equipment will be repaired. This determination is based on combat or combat support equipment, time, urgency, materials, and personnel required to execute repairs [4] [5]. The examples are shown in Scheme 1 and Scheme 2.

\subsection{System Assessment Summary}

1) Determine vehicle status.

- Can the vehicle shoot, move, and communicate?

- Can the vehicle be repaired to shoot, move, and communicate?

- Can the vehicle be self-recovered, towed, or transported?

2) Check engine, transmission, fuel system, electrical system, wheels and suspension, hydraulic system, armour/ammunition storage, armament/fire control, and communications to see if they can be repaired or recovered and identify any limitations.

3) Identify expendables, parts, and tools and National Stock Number (NSN) if applicable.

4) Estimate the time and personnel needed.

\subsection{Damage Assessment and Repair of Wheeled and Tracked Vehicles Hull}

1) Record applicable NSN for exchanged and cannibalized parts;

2) Check engine system — for example, starter, oil tank, air induction system, air cleaner, oil filter, drain valve, accessory drive, shaft, low oil pressure;

3) Check transmission and final drive systems for faults, for example transmission will not shift, broken linkage, vehicle will not steer, final drive locked, transmission leaks, parking and service brake serviceability, and oil cooler;

4) Check fuel systems—-for example, fuel tanks, fuel lines, fuel filters, fuel pumps;

5) Check electrical systems-for example, wiring harness, slip ring, batteries, circuit breakers, and power distribution box;

6) Check track and suspension systems, for example compensating idlers, track adjusting link, road wheel arms, road wheels, support rollers, sprockets, shock absorbers, torsion bars, and track assembly;

7) Check hydraulic systems lines and fluids, driver controls, and instruments. 


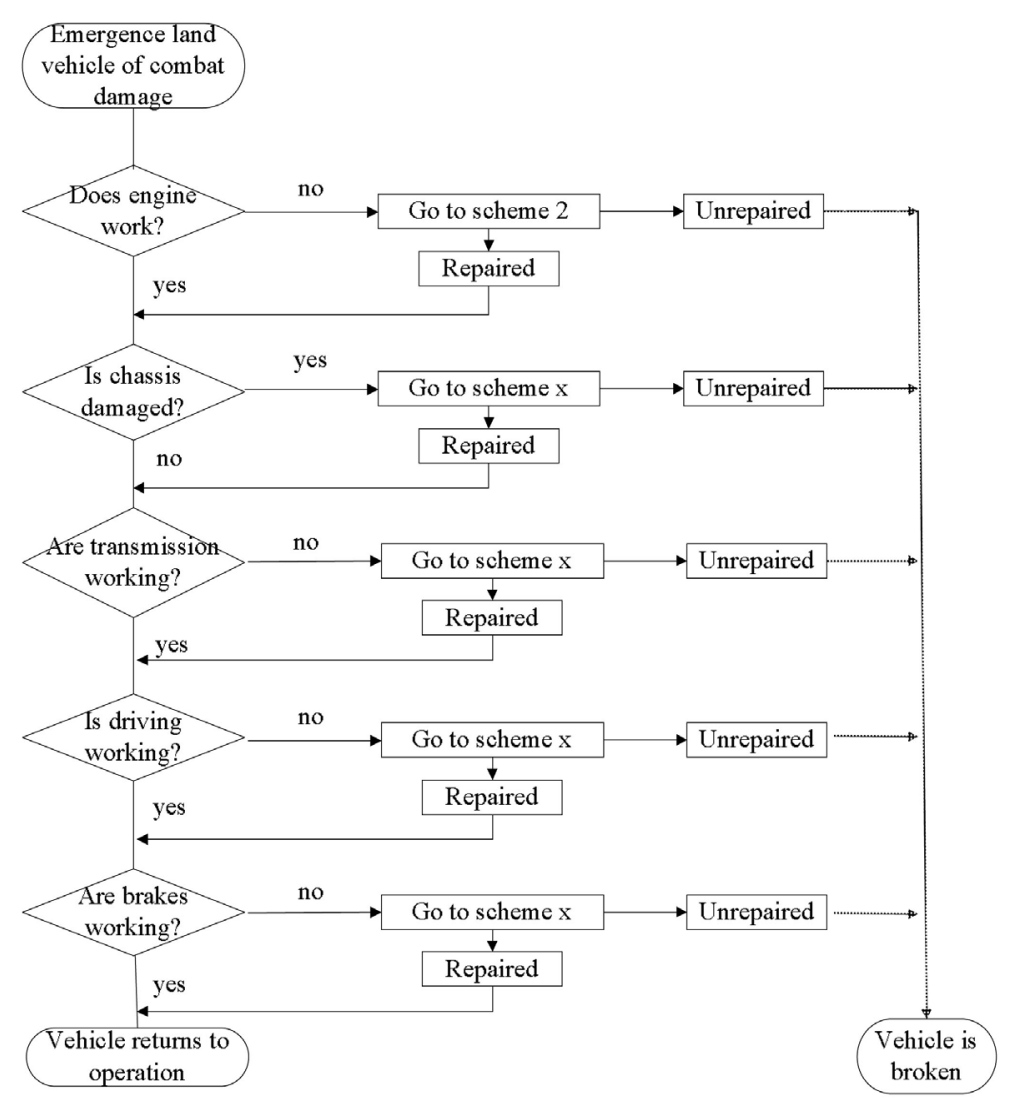

Scheme 1. Design of battle damage assessment and repair of land vehicle [6].

\subsection{Communications Damage Assessment and Repair}

1) Record applicable NSN for exchanged and cannibalized parts;

2) Check serviceability of intercommunications, receiver, transmitter, antennas, cables, and security.

\subsection{Turret Damage Assessment and Repair}

1) Record applicable NSN for exchanged and cannibalized parts;

2) Check electrical system — for example turret power, slip ring, circuit breaker, and wiring harness;

3) Check armament-for example, bore evacuator, gun tube, breech group, and main gun mount;

4) Check fire control system - for example, commander control handle and weapon sight, gunner primary and auxiliary sight, range finder, crosswind sensor, wiring system, gunner control handle, stabilization system, manual traverse and elevation, and loader's panel;

5) Check hydraulic system—-for example, auxiliary hydraulic pump, hydraulic fluid, and hydraulic reservoir.

\section{Technologies Used for Temporary Repairs and Results Achieved during Testing}

Adhesive composites have an important position in the field of temporary repair. These materials are able to withstand great loads on a created joint. In order to achieve the required parameters it is necessary to use the material with very good adhesive and cohesive properties. These two forces should be balanced.

It is obvious, that the composites with great ability of intermolecular interaction between glue and basic surface are used in present days. These materials are applicable for joints strained by pressure and slide staining. Adhesive composites are not adequate for pulling stressed joints, and for joints strained by peeling stress they are unusable [6].

For the specific testing and for the objectives of our research we have selected those which are used on a large scale by other NATO army kits and there exist also good references with their application. 


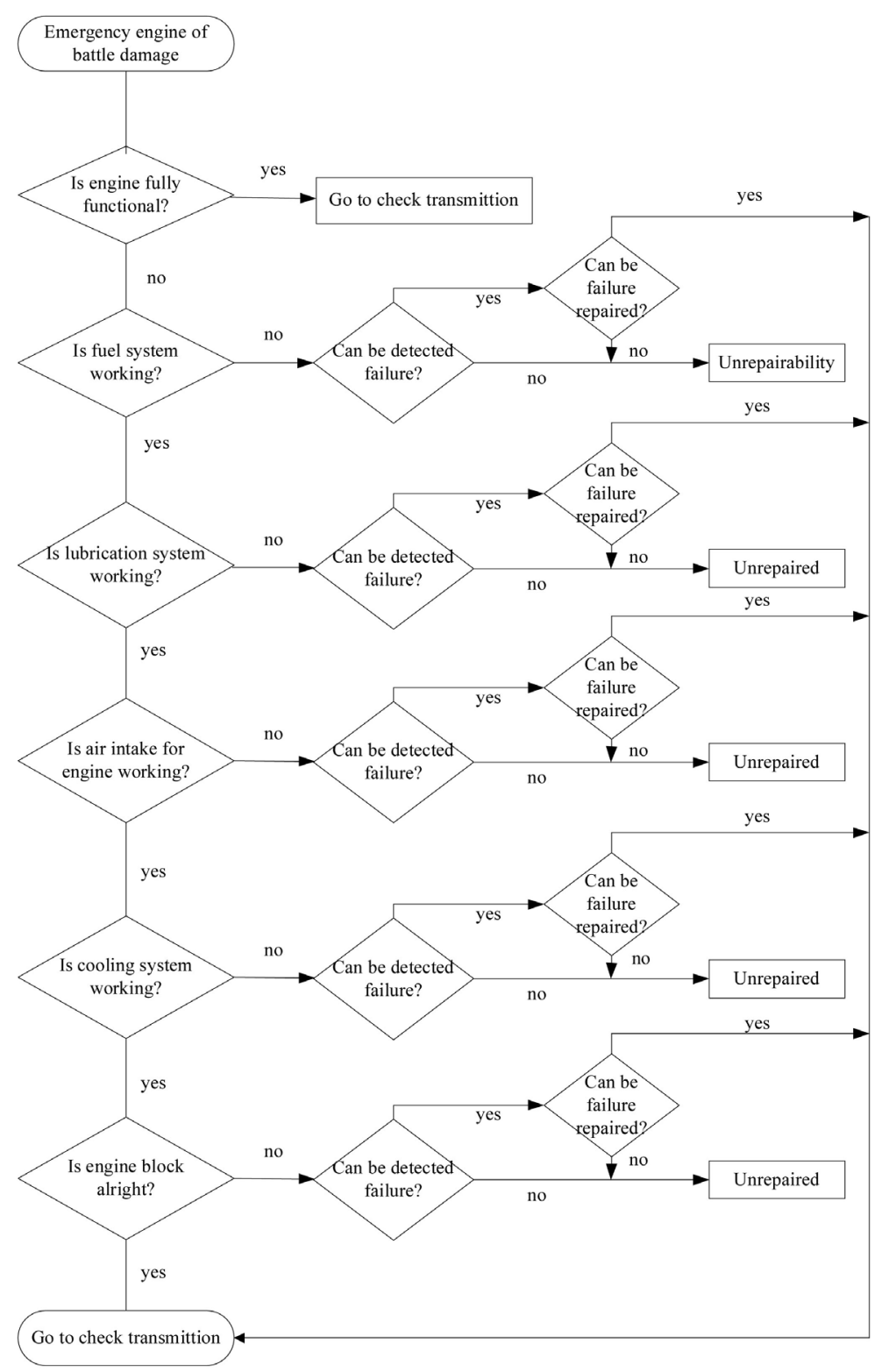

Scheme 2. Design of battle damage assessment and repair of engine [6].

\subsection{Adhesive Composite Belzona 1221}

The possible use of this sealant was taken from the American BDAR kit. Belzona 1221 is an all-purpose fast curing polymer based cement (sealant), which is able to withstand big stress in case of partial or full immersion, also influenced by high temperatures (sealant is recently used in the field of permanent repairs and anti-corrosion protection in thermal power engineering). Solidified sealant could be machined with all conventional methods (turning, milling and drilling). The sealant is also inert against all operating fluids used in vehicles.

The sealant is workable in $5^{\circ} \mathrm{C}-30^{\circ} \mathrm{C}$ temperature range; the repaired part is fully strainable after 72 minutes at $20^{\circ} \mathrm{C}$. Full chemical resistance sealant is obtained after 24 hours. Complete times for each strains are inserted in Table 1, these times are stated for a 6 mm layer of Belzona 1221 [7]. It takes a shorter time to cure thinner layers and a longer time to cure thicker layers.

Joints bonded with Belzona 1221 were tested during the study and these tests were executed according to the standard ISO EN 13445. This test is executed to determine share strength of adhesive bonds between rigid substrates using a block share method [8]. 
Table 1. Times needed for Belzona 1221 curing in different temperatures [4].

\begin{tabular}{ccccc}
\hline Temperature $\left({ }^{\circ} \mathrm{C}\right)$ & $\begin{array}{c}\text { Movement without } \\
\text { stress or dip (min) }\end{array}$ & $\begin{array}{c}\text { Machining or soft } \\
\text { stress (min) }\end{array}$ & $\begin{array}{c}\text { Full mechanical or } \\
\text { thermal strain (min) }\end{array}$ & $\begin{array}{c}\text { Dip in chemicals } \\
(\mathrm{h})\end{array}$ \\
\hline 5 & 17 & 60 & 120 & 48 \\
10 & 16 & 50 & 100 & 36 \\
15 & 15 & 45 & 90 & 30 \\
20 & 14 & 40 & 75 & 24 \\
25 & 13 & 35 & 60 & 20 \\
30 & 12 & 30 & 45 & 16 \\
\hline
\end{tabular}

The test of bonded joints was executed on Zwick 2100 machine (Figure 1). The test was executed by the method of measuring pull force to determine yield strength and rupture points.

The main purpose of this test was to consider the suitability of various bonding materials used for joining constructional materials applied frequently in combat and special vehicles construction. Determining the maximum force needed to rupture bonded joints was sufficient for purpose of this study.

For testing frequently repaired materials were chosen such as aluminum ČSN 424201 and steel ČSN 11373 which is common constructional steel. The main reason why other materials were not chosen was good machinability to required dimension and roughness, and there was not supposition of reaching yield strength of substrates during testing. It could be confirmed that the testing of sealant and glue ability to connect materials, which were chosen from big group of aluminum alloys and carbon steel used in automotive industry, two representatives are enough.

Five specimens of both materials were tested on Zwick 2100 machine. Rupture forces of bonded joints are put in a chart (Graph 2).

Unequally stressed one-sided lap joints cause the beginning of peeling. This explains the differences between rupture forces. Regarding the specimen rupturing deeply under $1000 \mathrm{~N}$ level, it can be concluded that the bonded joint was not well prepared or there was a pulse stress during the specimen deposition in a clamp jaw. Although the standard is dedicated to testing all bonded joints, it can be said that the standard is more convenient to test elastic joints. In case of the bonded joints of materials which acquire greater hardness after curing them it would be appropriate to design a bigger dimension of a lap with the necessity to increase tested substrates thickness.

The median of measured specimens population of a steel material is $1363.3 \mathrm{~N}$ and of an aluminum alloy is 1257.9 N which concludes that Belzona 1221 is applicable for both tested materials. The presence of Belzona 1221 in the BDAR kit is expedient because of its useful qualities which are resistance to stress, high temperatures and operational fluids. During this study Belzona 1221 was tested for TRs of fuel and pneumatic pipes with a various grade of damage. Because of a high filling quality Belzona 1221 could be used to repair diverse sizes of perforations of fuel or oil tanks. In case the perforations are bigger than $5 \mathrm{~mm}$, a reinforcement fabric was used. It is also possible to use Belzona 1221 to restore tightness and partly mechanical qualities of axles and gearboxes. Even the materials which are hard to weld can be also repaired with this sealant, such as cylinder heads or engine blocks made of aluminum alloy, or cast-iron.

The undeniable advantage of its use is the possibility of removing an applied layer of this material without the depreciation of a base material including a thermally influenced section, changed material micro-structure (e.g. in case of welding) and a related quality change of a repaired part. In view of this fact, the part repaired this way could be regularly repaired at higher levels of corrective maintenance subsequently.

During our research, the advantageousness of sealant Belzona 1221 was tested mainly when repairing high pressure pipes which were artificially perforated. Three types of perforation were produced; first one was a longitudinal crack with constant perforation width $2 \mathrm{~mm}$ in width and $50 \mathrm{~mm}$ in length. Secondly, there was prepared a large crack reaching the half of a pipe diameter which was in this case $15 \mathrm{~mm}$. These two types were repaired using a reinforcement fabric. Five cracks of various dimensions were created on third type of specimen. The damage was repaired only with the use of the sealant without any reinforcement fabric so that we could see eventual dependence on a crack size while the pipe is pressured. To obtain acceptable results, specimens were cyclically strained with various velocities of pressure increment. Each specimen was strained for 10 minutes to obtain satisfying results. All the specimens repaired this way resisted the maximum pressure load of $5 \mathrm{MPa}$ 


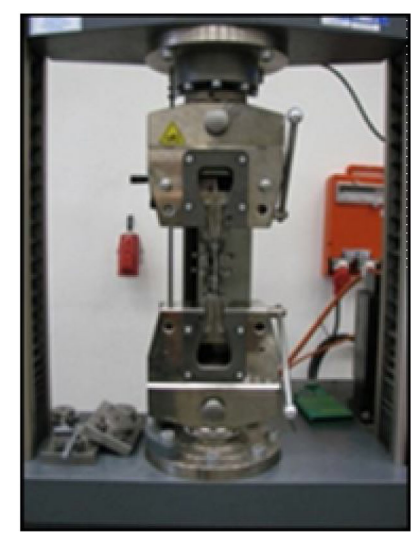

Figure 1. Zwick 2100.

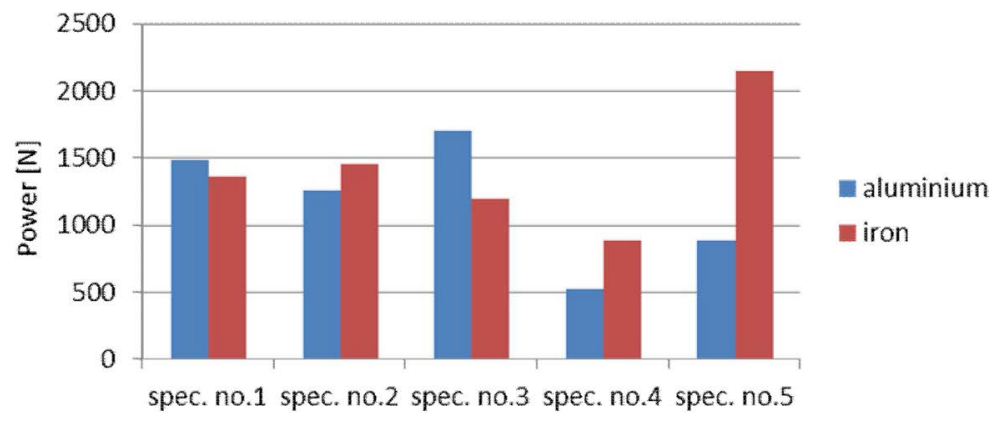

Graph 2. Rupture forces of specimens bonded by Belzona 1221. (Own Source)

which was the maximum reachable pressure of a hydraulic testing device (Figure 2).

Considering this fact Belzona 1221 could be viewed as a convenient way to repair pneumatic or hydraulic solid ducting of high pressure systems of military trucks and combat vehicles which operate with pressures up to $5 \mathrm{MPa}$.

In conclusion it has to be said that the Belzona 1221 fits more for newly appeared rifts and cracks, it fewer fits to repair glued joints.

Sealant can be appropriately used also in higher repair levels (such as technician platoon) for part renovation, can be mentioned repairs of damaged or wear out shafts, cylinder head cracks and bearing repair.

\subsection{Adhesive Composite Loctite 3450}

The necessity to include this two component glue was motivated by a need to have in a BDAR kit a tool used for repairing and assembling dismountable joints in vehicles. This product was chosen mainly as a result of good references given by users of various industry and repair sectors. The biggest advantage of this glue is that it can be used universally. Loctite 3450 bonds metal and plastic materials and it is resistant to recently used operational fluid too. The glue reaches the biggest strength after 4 hours and the curing progress can be described as linear [4]. One of the qualities of this glue is relatively big elasticity which can be seen on a stress-strain curve (Graph 3). The whole course of the curve can be defined as elastic which means that the specimen turns back to its original length. Following these facts the joint seems to be more pulse stress resistant than in case of Belzona 1221.

The test of the specimen projected this way was executed in the same manner as in previous case. The obtained rupture forces are shown in chart (Graph 4).

The chart shows that the required forces are doubled in comparison with Belzona 1221 sealant. It is important to notice that its application is beneficial especially in case of carbon steel bonding when the fissure is thinner than $3 \mathrm{~mm}$. The reason why some specimens ruptured bellow $1000 \mathrm{~N}$ level is the wrong mixing proportion of glue components. This was caused by uneasy glue application from tube. The hardener put up bigger resistance than the binder. In practice it would be better to squeeze all the tube content, blend it, use the amount needed 


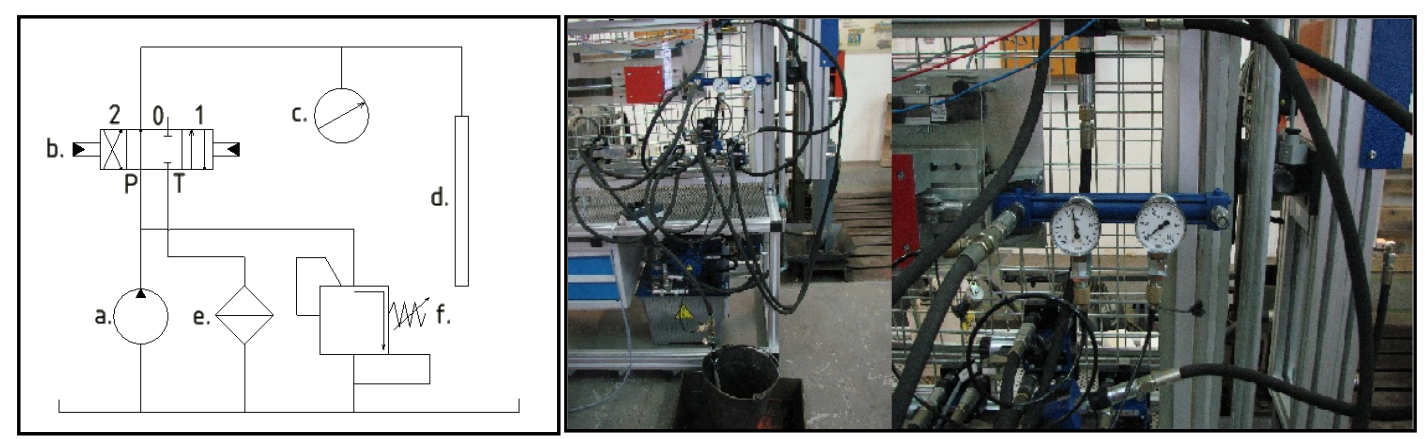

Figure 2. Scheme of testing hydraulic circuit and repaired pipes pressure resistance testing. (Own Source)

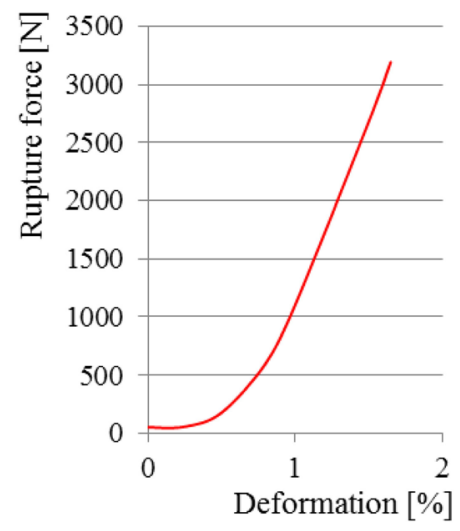

Graph 3. Proportional deformation reliance on force of Loctite 3450 bonded specimen. (Own Source)

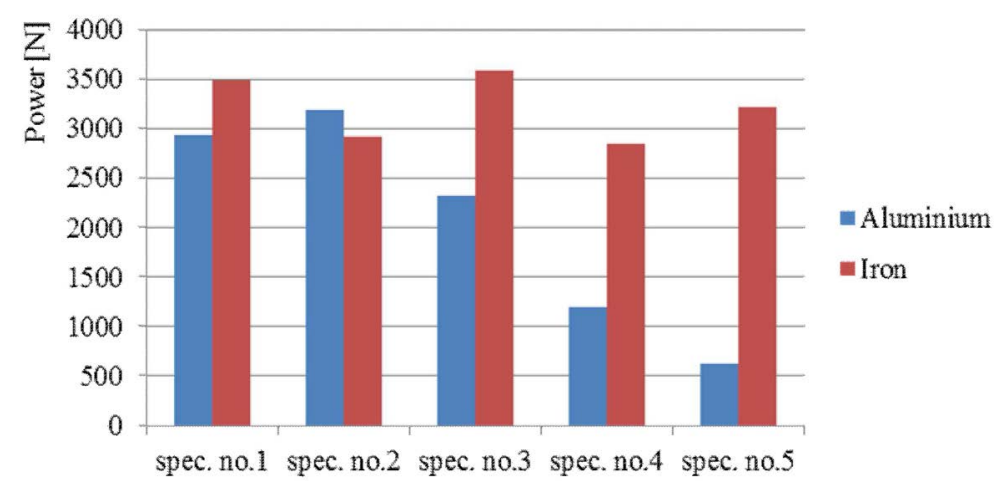

Graph 4. Rupture forces of Loctite 3450 bonded specimens. (Own Source)

and waste the rest.

The expediency of Loctite 3450 in field of temporary repair reside in perforation repair of plastic-metal coolers and their leak exactly in metal plastic surfaces. It is also possible to use it while repairing most of loose and fractured parts. Such as example shaft and hub mounting can be noticed and worn out cases molded joints. It is possible to repair worn out keyways, then to bond the key into the keyway and attach the hub (useful only in case of torque required for engine aggregate propulsion by belt pulleys, not in case of tens Nm-1 torque transmission).

The glue can be also used in the repairs of over tightened threads and threaded plugs on condition that some parts of thread still exist.

Loctite 3450 is also usable for patching leaking tanks with solid material patches even in cases when the patch is not made from the same material as a tank. 


\section{Temporary Repairs of Pneumatic and Hydraulic Hoses}

If we were to name the area where temporary repairs are really worth applying, it would be the damage of elastic pipes of operational agents.

The failure or damage of these parts often causes fatal consequences for vehicle operability. In order to rectify it, it is not always necessary to carry out complicated repairing procedures. The temporary repair should respect this.

\subsection{Loctite Teroson 5080 TM-Fix and Repair Tape}

The tape is a suitable supporting tool used for the temporary repairs of damaged low pressure hoses. Its application is very easy and takes just tens of seconds. The tape is waterproof and also resistant to a wide range of operational fluids. The disadvantage of its application is that only partly damaged hoses can be repaired. In case of $\mathrm{x}$-cross interrupted hoses the tape is useless.

The method is suitable for diesel management hoses, but not for petrol ones because of petrol greater fluidity. Cracked or rotten rubber hoses of cooling systems or vacuum engine regulations could be also repaired with the tape.

\subsection{Fittings for Plastic Hoses}

Hose fittings are ideal way to deal with damaged or burst hoses which are used for vehicles fuel systems in the Czech Army. Hose fittings are produced and supplied in various diameters. For the Czech Army the most useful fittings are the ones which are $8,10,12$, and $15 \mathrm{~mm}$ in diameter. Some parts of plastic hoses should be included in a BDAR kit to span larger damages. The similar tightness as in original joint is reached using hose fittings and their installation takes no longer than tens of seconds.

\subsection{High Pressure System Hoses Repairs}

High pressure hoses of hydraulic and pneumatic systems for example used to be reinforced by wired armature which guarantees their pressure resistance. To ensure the pressure resistance of the repaired high pressure hoses, the $\mathrm{x}$-cross section of a damaged part of hose is required.

The easiest way to repair a perforated or burst hose is to replace the damaged part using a larger diameter hose taken from the system of lower priority. The failure of that system does not directly influence vehicle operability. Pressure 0.48 MPa cannot be exceeded. This method seems to be useless in the Czech Army vehicles repair (e.g. in case of Tatra T-810 the operational air system pressure is above $0.85 \mathrm{MPa}$ level). This method can be used only in border-line cases and joint durability is not guaranteed. The better way of repairing 8 to $20 \mathrm{~mm}$ diameter hoses is to use hose connectors secured by hose clamps.

For TRs of larger diameter hoses the threaded fittings are convenient. The preparation of an x-cross section and subsequent fitting screwing is more time consuming, but on the other hand the hose repaired by this method has the same characteristics as a new one. It is because of conical contact in threaded fitting. In cases where a certain part of high pressure system disconnection does not have a negative influence on vehicle operability, some hoses can be blinded with conical plugs. In case of the replacement of longer parts of damaged hoses section a hose set can be used.

There was no need to test high pressure hoses repairs, because the pressure resistance of the above mentioned repair tools is guaranteed by the producer.

\section{Conclusions}

The main purpose of temporary repair execution is to restore vehicle operability in a relatively brief time interval (time needed up to 4.5 hours) using tools carried by a vehicle. The repair is assumed to be executed by a vehicles crew (usually the driver) directly in combat conditions and vehicle displacement will not be needed. In certain cases temporary repair can be carried out by specially trained personnel, using tools from special vehicles equipment which are designed especially for this purpose, for example recovery and workshop vehicles. The main disadvantage of this method is the prolongation of time needed for repair.

On the other hand one of the advantages of temporary repair is a very fast return of a vehicle to an operational 
state without necessity to transport the vehicle to a repairer units post. Temporary repairs are expedient especially in case of easy viable repairs which have fundamental influence on vehicles operability.

There is a growing interest of NATO members in the area of temporary repairs. The participation of the Czech Army in some operations makes us give bigger attention to this branch. In peacekeeping operations a well projected temporary repair system appears to be vital in questions of fighting efficiency and survivability.

The main interest of this paper lies in selecting, testing and outlining certain sum of tools and material useful for temporary repairs executing and which can be applied within the Czech Army conditions, especially in the field of mechanical parts, pneumatic and hydraulic system temporary repairs.

Another no less important objective was to formulate technological procedures leading to the effective appliance of tools included in the Czech BDAR kit. Although the tools of the BDAR kit are easily applicable, it is also necessary to pay considerable attention to vehicles crew training. A tactical level (a vehicle crew) has to be able to recognize in which situation the BDAR kit can be used and when it is necessary to call for assistance.

The BDAR kit previously mentioned cannot be considered to be final and invariable because of the evolution of new technologies and materials. Those things constantly offer brand new possibilities in the temporary repair field and eventually can alter the proposed content.

\section{Acknowledgements}

The presented work has been prepared with the support of the Ministry of Defence of the Czech Republic, Partial Project for Institutional Development, K-202, the Department of Combat and Special Vehicles of the University of Defence, Brno.

\section{References}

[1] Smal, T. (2011) Battle Damage Repair Systems of Selected Armies of NATO. Proceedings of Deterioration, Dependability, Diagnostics, University of Defence, Brno, 33-42.

[2] ČSN EN 13306 (2002) Maintenance Terminology. Český Normalizační Institute, Praha.

[3] Furch, J. and Smal, T. (2011) Expedient Repairs-Analysis of Possibilities and Needs. Advances in Military Technology, 6, 69-82.

[4] FM 4.30-31 (2006) Field Manual Recovery and Battle Damage Assessment and Repair.

[5] GTA 01-14-001 (2012) Battle Damage Assessment and Repair.

[6] Rośkowicz, M. and Smal, T. (2007) Static Long-Lasting Life of Adhesive Composite in Shear Loaded Joints. Technology and Assembly Automation, 2, 112-115.

[7] Belzona 1221 (2013) Super E-Metal User Manual. Belzona, Harrogate.

[8] EN ISO 13445 (2006) Adhesives: Determination of Shear Strength of Adhesive Bonds between Rigid Substrates by the Block-Share Method. Management Centre, Brussels. 
Scientific Research Publishing (SCIRP) is one of the largest Open Access journal publishers. It is currently publishing more than 200 open access, online, peer-reviewed journals covering a wide range of academic disciplines. SCIRP serves the worldwide academic communities and contributes to the progress and application of science with its publication.

Other selected journals from SCIRP are listed as below. Submit your manuscript to us via either submit@scirp.org or Online Submission Portal.
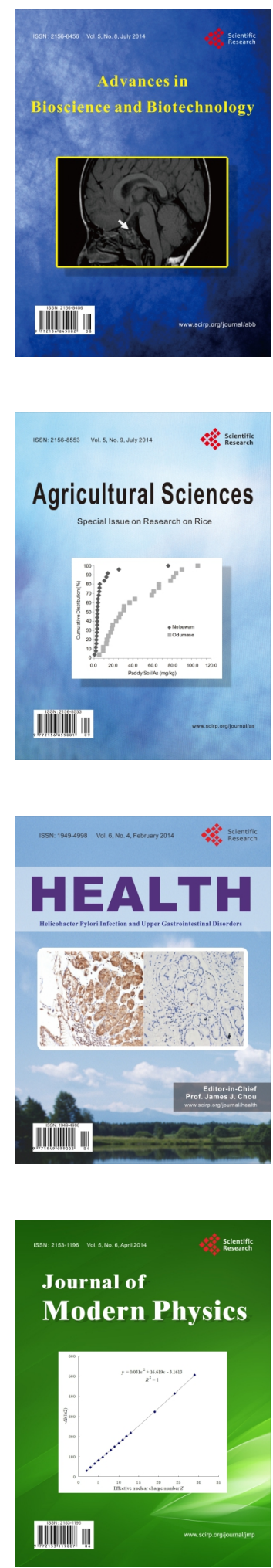
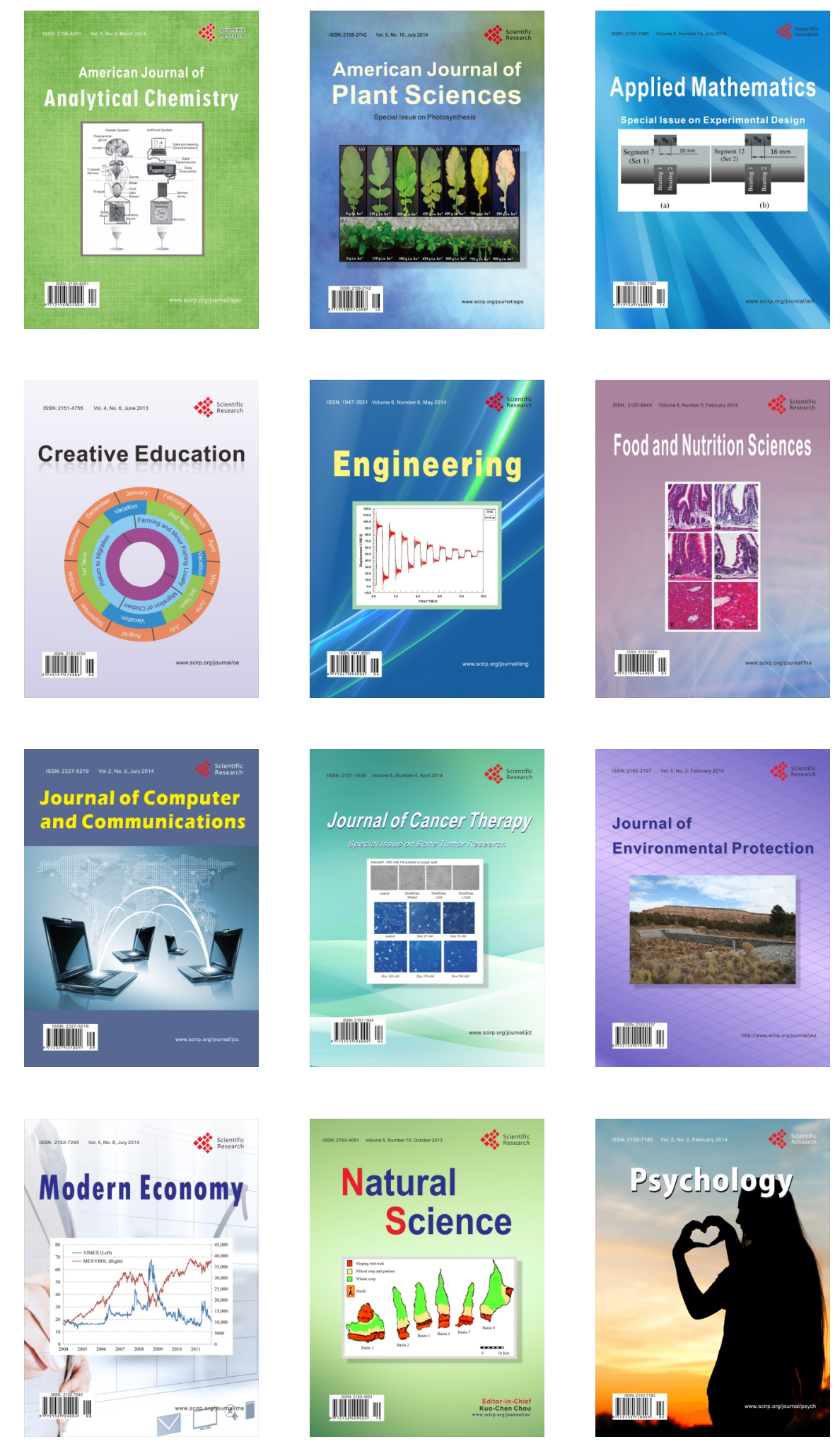